\title{
Relato de uma série de 30 casos presumíveis de neurorretinite subaguda unilateral difusa (DUSN)
}

\author{
Study of 30 cases of presumed diffuse unilateral subacute neuroretinitis(DUSN)
}

\author{
Marcus Augiusto Gomes de Matos ${ }^{1}$ \\ Denise Dantas Boudoux Silva ${ }^{1}$ \\ Silvana Aranha Trigueiro ${ }^{1}$ \\ Ana Lúcia de Andrade Lima Arcoverde ${ }^{2}$ \\ Sandra Dias ${ }^{3}$ \\ Marisa Zamora Kattah ${ }^{4}$
}

\begin{tabular}{|l|}
\hline RESUMO \\
\hline Objetivo: Relatar uma série de 30 casos com características de \\
neurorretinite subaguda unilateral difusa em Pernambuco e descrever os \\
aspectos clínicos e epidemiológicos. Métodos: Análise retrospectiva de \\
30 pacientes com neurorretinite subaguda unilateral difusa, atendidos no \\
ambulatório de uveítes da Fundação Altino Ventura e do Hospital de \\
Olhos de Pernambuco, de janeiro de 1998 a abril de 2000 . Resultados: Em \\
relação ao sexo, 20 pacientes (66,7\%) eram do sexo masculino. A idade \\
variou de 7 a 40 anos com média de idade de 18,1 anos (s $=6,9)$. O olho \\
esquerdo foi acometido em 15 casos ( $50,0 \%$ ). A acuidade visual para \\
longe com a melhor correção era igual ou pior do que $20 / 400$ em 29 casos \\
(96,7\%). Os achados fundoscópicos foram considerados graves em mais \\
da metade dos casos. Palidez do disco óptico grave em 20 casos ( $66,6 \%)$, \\
estreitamento vascular retiniano grave em 16 casos ( $53,3 \%$ e atrofia do \\
epitélio pigmentar retiniano grave em 15 casos $(50,0 \%$. Conclusão: \\
Devido ao fato de, em nenhum dos pacientes, haver sido encontrada \\
larva no espaço subretiniano e conseqüente realização de tratamento \\
adequado, os casos relatados neste estudo apresentaram avançado grau \\
de acometimento ocular e importante baixa da acuidade visual.
\end{tabular}

Descritores: Retinite/diagnóstico, Retinite/epidemiologia; Infecções oculares parasitárias/diagnóstico; Neuritie óptica/epidemiologia

\footnotetext{
${ }^{1}$ Médicos alunos do terceiro ano do curso de especialização em oftalmologia da Fundação Altino Ventura.

2 Médica do departamento de Retina da Fundação Altino Ventura / Hospital da Olhos de Pernambuco.

Médica da Fundação Altino Ventura / Hospital da Olhos de Pernambuco. Coordenadora do departamento de uveítes.

${ }^{4}$ Médica da Fundação Altino Ventura / Hospital da Olhos de Pernambuco. Coordenadora do departamento de neurooftalmologia.

Endereço para corresponência: Fundação Altino Ventura - Rua da Soledade, 136 - Boa Vista, Recife (PE) CEP 50070-020. Telefax: (0xx81) 421-4338.

E-mail: fundação@hope.com.br
}

\section{INTRODUÇ̃̃̃O}

Gass, em 1978, descreveu uma nova síndrome caracterizada por acometer um dos olhos, de pacientes adultos jovens, denominada inicialmente unilateral wipe out syndrome. Posteriormente, com análise de maior número de casos, examinados em fases mais precoces, o nome de neurorretinite subaguda unilateral difusa (Diffuse unilateral subacute neuroretinitis - DUSN), foi proposto ${ }^{(1)}$. No Brasil, Souza, em 1992, descreveu o primeiro caso confirmado de DUSN, com identificação de larva no espaço subretiniano $^{(2)}$ e, em 1999 , este mesmo autor descreveu o primeiro relato de caso de doença bilateral ${ }^{(3)}$. Acredita-se que no Brasil, a maior prevalência desta doença, seja encontrada nos estados do Nordeste ${ }^{(4)}$.

A doença afeta principalmente crianças e adultos jovens não sendo acompanhada de manifestações clínicas extra-oculares impor$\operatorname{tantes}^{(1-2,10-11,16,18,20)}$. Na fase inicial há diminuição da acuidade visual, inflamação no vítreo, papilite, vasculite retiniana e lesões retinianas evanescentes branco-acinzentadas. Na fase tardia, o quadro oftalmoscópico é de atrofia óptica com alterações difusas do epitélio pigmentar da retina $^{(1,10-13,15,18,20)}$. Aproximadamente $50 \%$ dos pacientes apresentam, no olho acometido, acuidade visual para longe igual ou pior a $20 / 200^{(15)}$. 
A etiopatogenia da DUSN está definitivamente relacionada à presença de uma larva no espaço subretiniano que poderia ser de um nematóide ou de trematóide ${ }^{(1,3-5,10-15,18,20)}$. As larvas se caracterizam pela mobilidade, coloração branca, por vezes brilhante, tamanho variável entre 350 e 2000 micrômetros de comprimento, sendo a largura 20 vezes menor que o comprimento $^{(14,18-19)}$. Observou-se em alguns casos aumento da motilidade com iluminação ${ }^{(12-13,18)}$.

Acredita-se que esta doença faça parte de uma síndrome de etiologia múltipla, causada por várias espécies, de acordo com a localização geográfica. Dentre as mais citadas destacam-se o Toxocara canis no Brasil e o Baylisascaris procyonis no noroeste dos Estados Unidos ${ }^{(1,5-6,10,13-16,18,20)}$. Além destes, o Ancylostoma caninum, o Ancylostoma brasiliense, o Onchocerca volvulus, o Loa loa, a Wuchereria brancofti e a Alaria mesocercaria ${ }^{(5,10,18,20,24)}$ também são possíveis agentes.

O diagnóstico de certeza só é realizado quando é feita a localização da larva no espaço sub-retiniano. A eletroretinografia na DUSN, em particular, pode ser útil. A onda b é usualmente mais atingida que a onda a com a relação $b / a<1^{(4,7-8,12,15,19)}$. Quanto ao tratamento da DUSN, apenas a fotocoagulação da larva, nas fases iniciais da doença, pode impedir o seu avanço e até mesmo proporcionar recuperação parcial da acuidade visual $^{(9-12,15,18,20,23)}$. O tratamento medicamentoso, com tiabendazol, ivermectina e dietilcarbamazina, não são eficientes, na maioria dos $\operatorname{casos}^{(1,4,12-15,22)}$ e o tratamento cirúrgico, pode ser indicado em casos selecionados ${ }^{(5,14-16,21)}$.

O presente estudo tem como objetivo relatar uma série de 30 casos com características de neurorretinite subaguda unilateral difusa atendidos em Recife (Pernambuco) e descrever os aspectos clínicos e epidemiológicos.

\section{MÉTODOS}

Trata-se de um estudo clínico retrospectivo de 30 pacientes com quadro clínico de DUSN, atendidos no ambulatório de uveítes da Fundação Altino Ventura e do Hospital de Olhos de Pernambuco, no período de Janeiro de 1998 a Abril de 2000.

Devido a não identificação da larva no espaço subretiniano, o diagnóstico presumível foi baseado na história clínica, achados oftalmológicos e estudos laboratoriais. Realizaramse diagnóstico diferencial com outras doenças, de acordo com a necessidade de cada caso. Em 20 pacientes $(66,7 \%)$ realizouse retinografia e angiografia fluoresceínica.

Consideraram-se, como critérios de inclusão para o presente estudo, os pacientes que apresentavam história clínica e achados fundoscópicos de: curso progressivo da doença, atingindo crianças e adultos jovens e sadios; brilho exagerado focal sectorial ou difuso da membrana limitante interna da retina; pontos brancos calcificados na retina e túneis retinianos; alterações difusas do epitélio pigmentar retiniano concomitantes com estreitamento vascular e palidez variável do disco óptico; ausência da migração pigmentária intra-retiniana tipo osteoblastos; ausência de história de trauma ocular anterior; caráter progressivo das lesões com baixa da acuidade visual e ausência de inflamação importante no segmento anterior ocular.

Todos os pacientes foram contactados, por busca ativa, para a realização de exames fundoscópicos com lente asférica de 78 dioptrias e de contato de Goldmann, com os objetivos de identificação da larva e de classificação dos achados fundoscópicos. A palidez do disco óptico, estreitamento vascular e atrofia do epitélio pigmentar retiniano foram classificados subjetivamente de uma a quatro cruzes, em ordem crescente, de acordo com o grau de acometimento (Tabela 1). Considerou-se como leve o acometimento classificado entre $1+\mathrm{e} 2+\mathrm{e}$ grave o entre $3+\mathrm{e} 4+$ (Tabela 2). Estes achados fundoscópicos foram escolhidos para classificação por já terem sido considerados em outro estudo ${ }^{(15)}$.

\section{RESULTADOS}

Em relação ao sexo, 20 pacientes $(66,7 \%)$ eram do sexo masculino e $10(33,3 \%)$ do sexo feminino. A idade variou de 7 a 40 anos com média de 18,1 anos $(s=6,9)$. O olho esquerdo foi acometido em 15 casos (50,0\%) (Tabela 1).

A acuidade visual para longe com a melhor correção variou de 20/40 a percepção e projeção luminosa. Em 24 pacientes $(80 \%)$ a acuidade visual era pior que 20/400 (Tabela 1 ).

Ao exame fundoscópico, não foi encontrado larva no espaço subretiniano. Não foi realizado diagnóstico presumível de doença bilateral.

\section{DISCUSSÃO}

A DUSN, clinicamente, apresenta acometimento unilateral, atingindo crianças e adultos jovens sadios, sem predileção por $\operatorname{sexo}^{(2,10-12,15,18,20)}$, mas, em raros casos, pode se apresentar bilateralmente ${ }^{(2,4)}$. Nesta série observou-se média de idade de 18 anos sem preferência pela lateralidade (olho esquerdo $50,0 \%)$. Houve predomínio de acometimento do sexo masculino $(66,7 \%)$, porém, nestes casos, não se observou quaisquer características especiais em relação aos achados oftalmológicos.

É importante estarmos atentos ao fato de que a DUSN presumida pode se enquadrar como diagnóstico diferencial das coroidites multifocais. $\mathrm{Na}$ fase inicial, as lesões podem ser confundidas com toxoplasmose multifocal, doença citomegálica, epiteliopatia placóide multifocal posterior aguda, síndrome dos pontos brancos evanescentes, doença Behçet e histoplasmose presuntiva, entre outras. Nas fases tardias, os principais diagnósticos diferenciais são com histoplasmose presuntiva, retinose pigmentária unilateral, coriorretinopatia traumática, atrofia coriorretiniana após obstrução da artéria central da retina e neuropatia óptica isquêmica anterior ${ }^{(10,18)}$. O diagnóstico de certeza só é realizado quando há a localização da larva no espaço subretiniano. 


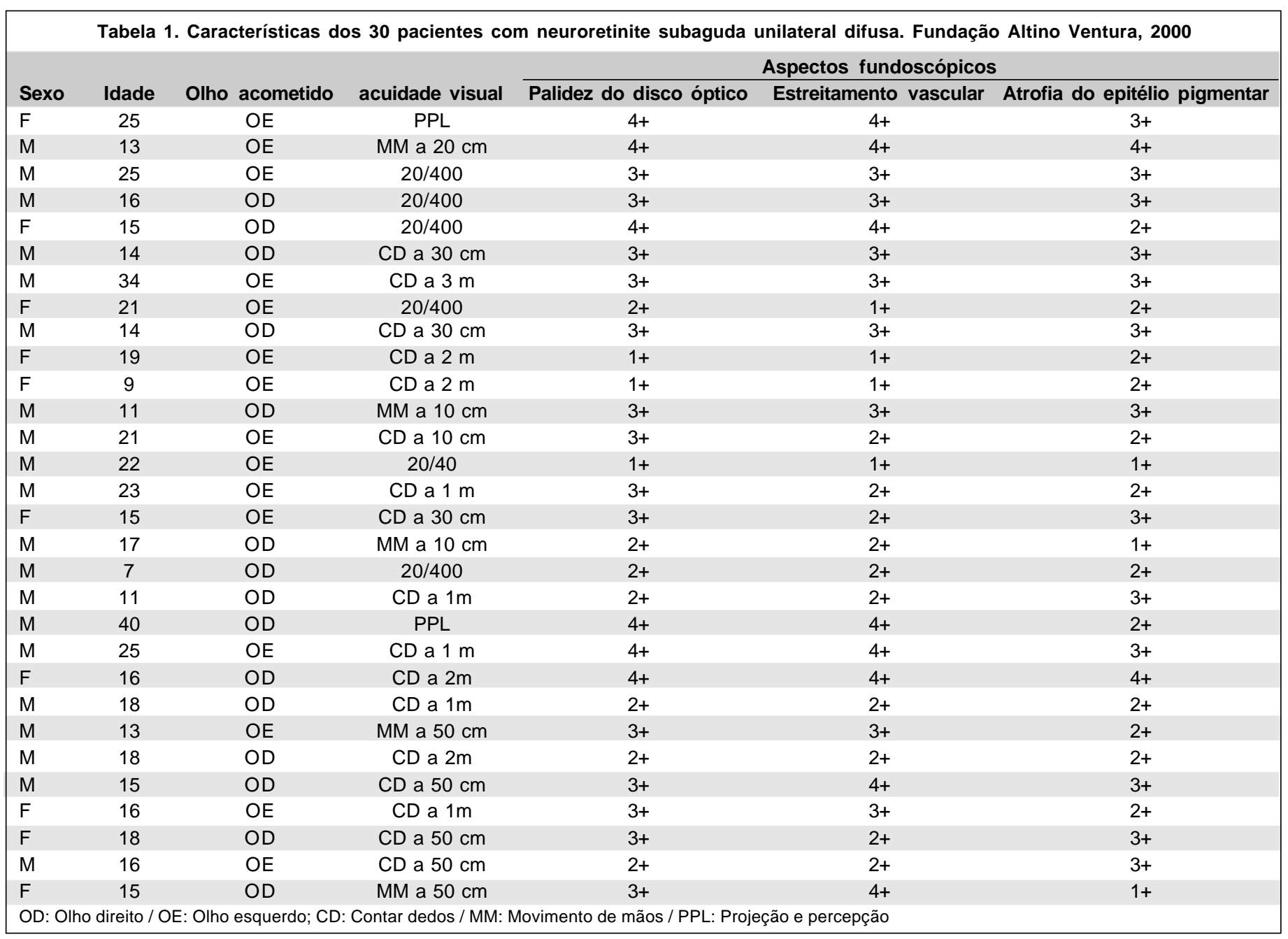

\begin{tabular}{|c|c|c|c|c|}
\hline & \multicolumn{2}{|c|}{ Leve } & \multicolumn{2}{|c|}{ Grave } \\
\hline & № & $\%$ & № & $\%$ \\
\hline Palidez do disco óptico & 10 & 33,3 & 20 & 66,6 \\
\hline Estreitamento vascular retiniano & 14 & 46,7 & 16 & 53,3 \\
\hline Atrofia do epitélio pigmentar retiniano & 15 & 50,0 & 15 & 50,0 \\
\hline
\end{tabular}

De acordo com os casos relatados no Brasil, as larvas usualmente variam entre 400 e 700 micrômetros de comprimento, exceto por um caso descrito (primeiro relato da América do Sul) de larva medindo entre 1500 e 2000 micrômetros de comprimento $^{(23)}$. Até então, larvas de tal tamanho só haviam sido descritas no Noroeste dos Estados Unidos e Alemanha ${ }^{(10,15,23)}$. É difícil a localização da larva. Acredita-se que apenas em 20 a $50 \%$ dos casos de DUSN a larva móvel é encontrada ${ }^{(4)}$. Oliveira e cols. ${ }^{(18)}$ relataram sete casos com diagnóstico clínico presumível, sem a localização da larva. Oréfice e cols. ${ }^{(12)}$ relataram 23 casos de DUSN, e, em apenas dois pacientes $(11,5 \%)$, houve a localização da larva no espaço subretiniano. Recentemente, este mesmo autor relatou dois pacientes com diagnóstico presumível de doença bilateral. Nestes dois casos, somente identificou-se a larva em um dos olhos de um dos pacientes ${ }^{(4)}$. Nos 30 casos apresentados nesta série, apesar de cuidadosos exames fundoscópicos, não foi possível localizar larva móvel em nenhum dos pacientes.

Sabe-se que as classificações subjetivas são falhas. Podem ocorrer variações entre diferentes examinadores e até mesmo na observação de um único examinador, em momentos distintos. Neste estudo, utilizou-se subjetivamente uma classificação, de acordo com o grau de acometimento ocular, em leve e grave. Foi observado que a maioria dos casos se apresentavam em estágio avançado da doença. Em $80 \%$ dos pacientes a acuidade visual para longe corrigida era pior que 20/400 (Tabela 1) e mais da metade dos casos apresentavam palidez do disco óptico, estreitamento vascular retiniano e atrofia do eptélio pigmentar retiniano (Talela 2) classificados como grave. $\mathrm{O}$ avançado grau de acometimento ocular se deveu ao fato de não termos identificado larva no espaço subretiniano. Isto nos impediu de deter a progressão da 


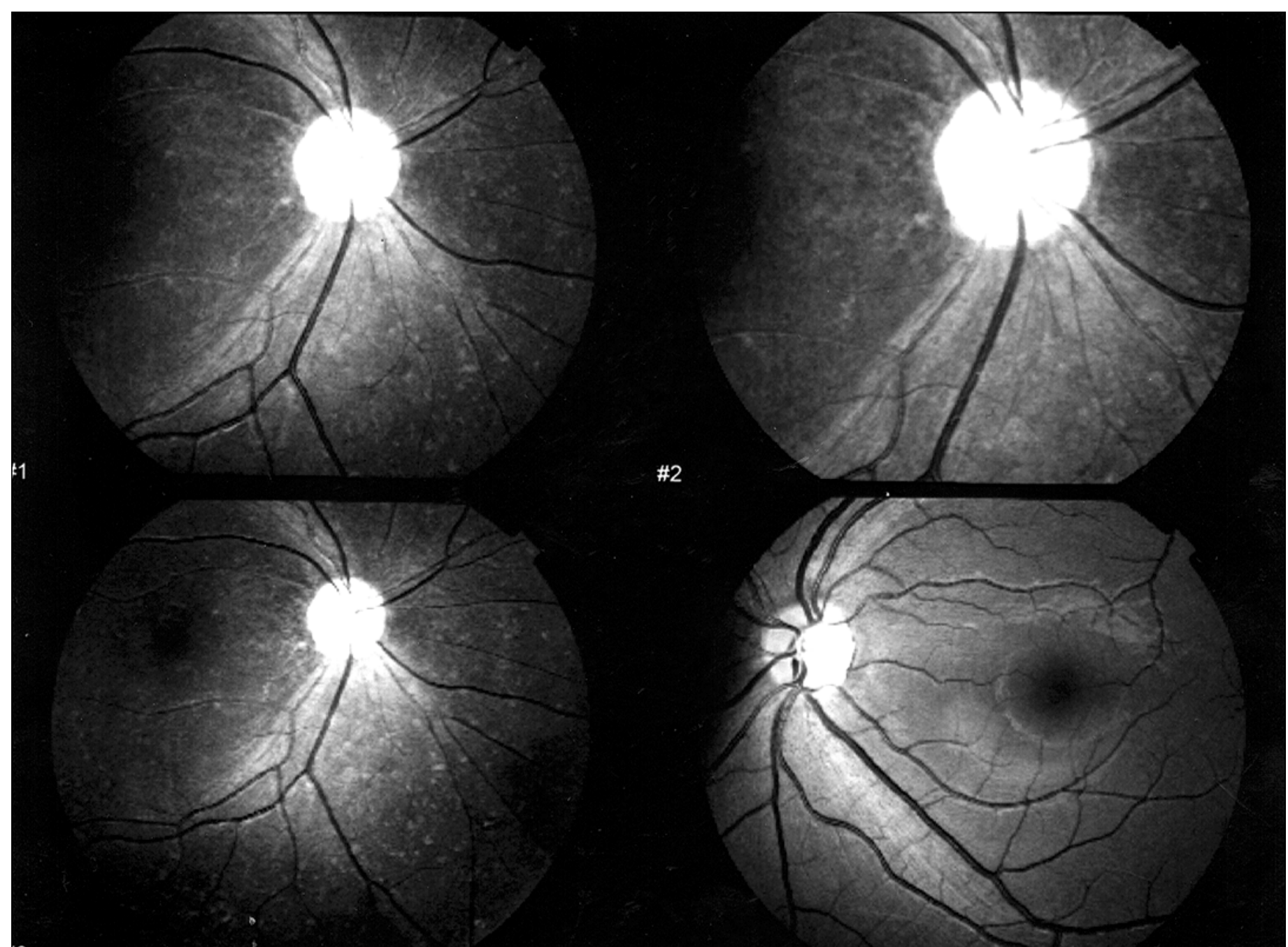

Figura 1 - Retinografia de um paciente onde se observa palidez temporal do disco óptico, estreitamento arteriolar e aumento do brilho da membrana limitante interna da retina além de acometimento unilateral. Fundação Altino Ventura 1998

doença, através de tratamento adequado por fotocoagulação, o que ocasionou graves consequências funcionais e fundoscópicas ao olho acometido.

\section{ABSTRACT}

Purpose: To report 30 patients with presumed diffuse unilateral subacute neuroretinitis in Pernambuco and describe the clinical and epidemiologic aspects. Methods: Restrospective analysis of 30 patients with presumed diffuse unilateral subacute neuroretinitis, assisted at the Uveitis Department of Fundação Altino Ventura and Hospital de Olhos de Pernambuco, from January 1998 to April 2000. Results: Twenty patients (66.7\%) were males. Regarding age, it ranged between 7 and 40 years. The average was 18.1 years $(s=6.9)$. DUSN was diagnosed in the left eye in 15 patients $(50.0 \%)$. Visual acuity was equal to or worse than 20/400 in 29 patients (96.7\%). Conclusion: We could not find the nematode in the subretinal space in any patient. This could explain why those patients had advanced ocular alterations and very low visual acuity.

Keywords: Retinitis/diagnosis; Retinitis/epidemiology; Parasitic eye infection/diagnoseis; Optic neuritis/epidemiology

\section{REFERÊNCIAS}

1. Gass JD, Gilbert Jr WR, Guerry RK, Scelfo R. Diffuse unilateral subacute neuroretinitis. Ophthalmology 1978;85:521-45.

2. Souza EC de, Cunha SL da. Neurorretinite subaguda unilateral difusa no Brasil: encontro da larva subretiniana. Arq Bras Oftalmol 1992;55:251-4.

3. Souza EC de, Abujamra S, Nakashima Y, Gass JD. Diffuse bilateral subacute neuroretinitis: first patient with documentei nematodes in both eyes. Arch Ophthalmol 1999;117:1349-51.

4. Oréfice F, Targino A, Coscarelli G, Ferro MJC, Lemos S. DBSN - Neurorretinite subaguda bilateral difusa: 2 casos clínicos. Rev Bras Oftalmol 2000;59(5):360-68.

5. McDonald HR, Kazacos KR, Schatz H, Johnson RN. Two cases of intraocular 


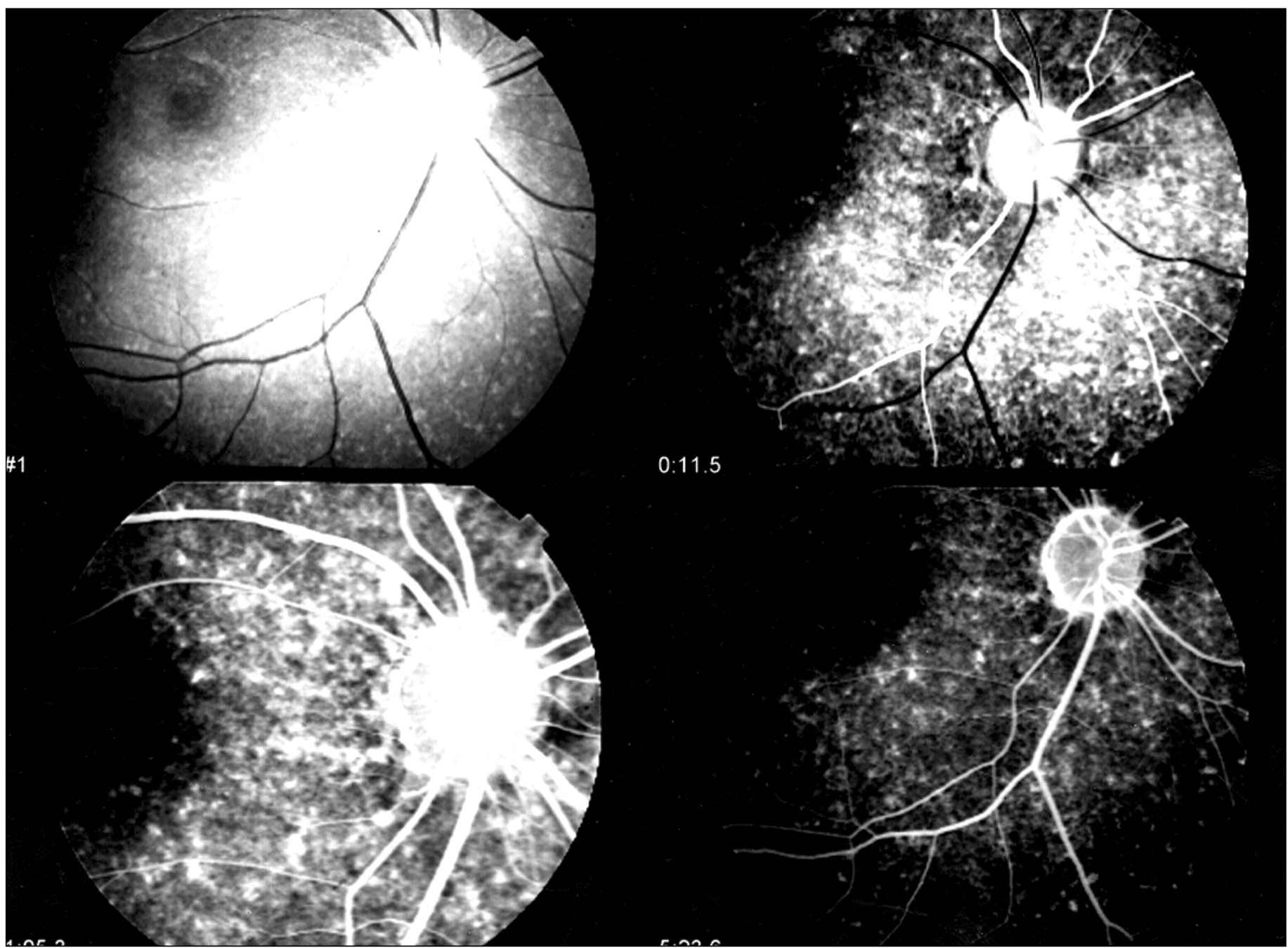

Figura 2 - Angiografia fluoresceínica de um paciente onde se observa palidez do disco óptico, aumento do brilho da membrana limitante interna da retina, alterações do EPR e estreitamento arteriolar. Fundação Altino Ventura 1998

infection with Alaria mesocercaria (Trematoda). Am J Ophthalmol $1994 ; 117: 447-55$.

6. Kazacos KR, Vestre WA, Kazacos EA, Raymond LA. Diffuse unilateral subacute neuroretinitis syndrome: probable cause. Arch Ophthalmol 1984; 102:967-8

7. Paranhos FRL, Ávila MP, Paranhos A, Cialdini AP. Estudo estatístico de valores normais do eletrorretinograma: contribuição à padronização do exame. Arq Bras Oftalmol 1997;60:278-84.

8. Paranhos FRL, Cialdini AP, Ávila MP. Electroretinogram in diffuse unilateral subacute neuroretinitis [abstract 1671]. Invest Ophthalmol Vis Sci. 1997;37:S361

9. Amaro MH, Orlock D. Investigação do envolvimento coroidiano na neurorretinite difusa unilateral sub-aguda. Rev Bras Oftalmol 1997;56:785-90.

10. Souza EC de, Cunha SL, Gass JD. Diffuse unilateral subacute neuroretinitis in South America. Arch Ophthalmol 1992;110:1261-3.

11. Goldberg MA, Kazacos KR, Boyce WM, Ai E, Katz B. Diffuse unilateral subacute neuroretinitis. Morphometric, serologic, and epidemiologic support for Baylisascaris as a causative agent. Ophthalmology 1993; 100:1695-701.

12. Oréfice F, Gonçalves ER, Siqueira RC, Nehemy MB. Estudo de 21 casos de neurorretinite subaguda unilateral difusa (DUSN); dois casos de larva móvel sub-retiniana. Rev Bras Oftalmol 1994;53:23-45.

13. Kazacos KR, Raymond LA, Kazacos EA, Vestre WA. The raccoon ascarid. A probable cause of human ocular larva migrans. Ophthalmology 1985;92:1735-44.

14. Souza EC de, Nakashima Y. Diffuse unilateral subacute neuroretinitis. Report of transvitreal surgical removal of a subretinal nematode. Ophthalmology 1995;102:1183-6.

15. Gass JDM, Braunstein RA. Further observations concerning the diffuse unilateral subacute neuroretinitis syndrome. Arch Ophthalmol 1983;101:1689-97.

16. Carney MD, Combs JL. Diffuse unilateral subacute neuroretinitis. Br J Ophthalmol 1991;75:633-5.

17. Matsumoto BT, Adelberg DA, Del Priore LV. Transretinal membrane formation in diffuse unilateral subacute neuroretinitis. Retina 1995;15:146-9.

18. Oliveira AA, Oréfice F. Estudo de sete casos neuroretinite difusa subaguda unilateral. Rev Bras Oftalmol 1992;51:51-5.

19. Veiga-Reis F, Oréfice JL, Nehemy MB, Oréfice F. Neurorretinite sub-aguda unilateral difusa - Videoangiografia digital com indocianina verde e eletrorretinograma. Rev Bras Oftalmol 1999;58:525-3.

20. Casella AMB, Farah ME, Bonomo PP, Souza EC. Neurorretinite subaguda unilateral difusa: 3 casos no estado do Paraná. Arq Bras Oftalmol 1994;57:77-9.

21. Biglan AW, Glickman LT, Lobes Jr LA. Serum and vitreous Toxocara antibody in nematode endophthalmitis. Am J Ophthalmol 1979;88:898-901.

22. Casella AM, Farah ME, Belfort Jr R. Antihelminthic drugs in unilateral subacute neuroretinitis. Am J Ophthalmol 1998;125:109-11.

23. Cialdini AP, Souza EC de, Ávila MP. The first South American case of diffuse unilateral subacute neuroretinitis caused by a large nematode. Arch Ophthalmol 1999;117:1431-2.

24. Medeiros A, Gonçalves ER. Filariose intra-ocular: apresentação de um caso de localização sub-hialoidea da Wuchreria bancrofti. Arq Bras Oftalmol 1995;58:169-74. 